scores as "reflective of what's typical of her ethnicity and gender", but her grit score as off the charts. "That's a person who will start graduate school way ahead of the game, with all the resources and skills that go beyond smarts: self-discipline, organization, follow-through," says Stassun. "Far too often, graduate programmes ignore that." Bastien's grit has paid off: this year she appeared as the first author of a Nature paper defining a new, relatively easy and more precise way to calculate a star's evolutionary age (F. A. Bastien et al. Nature 500, 427-430; 2013).

Duckworth cautions that assessing grit in such high-stakes settings as graduate admissions is tricky. "The grittiest people are often the least willing to say they are gritty," she says. Moreover, she adds, the higher the stakes, the greater the incentive the interviewee has to provide phony or

出 insincere answers.

"You can interview

for social intelli-

gence on the spot,"

Duckworth says.

"But I don't know

that you can assess

whether [the can-

didate] will be

awake at 6 a.m. the

next morning - or

if after their first

major screw-up,

they are going to

give up." She still

thinks that screen-

ing for grit might

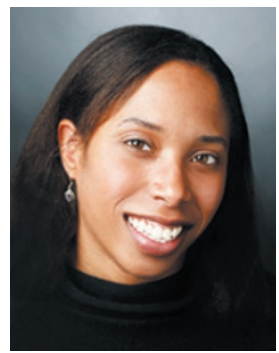

"I was afraid of graduate school. Ithought I had to be much more prepared." Fabienne Bastien be worthwhile, but

how best to measure it remains uncertain.

Regardless, the Fisk-Vanderbilt students exemplify the grit quality, and they say that the programme's focus on character building sets it apart from other minority initiatives. Tross is currently struggling in a Vanderbilt class on advanced molecular genetics. She is relying on her grit to get her through. "I've cried my tears. I've weighed whether I'm going to pass or not. But I'll keep doing the work," she says.

\section{EXPANDING HORIZONS}

Other universities are taking note of the FiskVanderbilt success. Abigail Stewart, who has been involved in setting up the programmes at the University of Michigan in Ann Arbor, says that all science-graduate admissions committees could learn from the Fisk-Vanderbilt model. "In general, we are eager to use simple tests or cut-offs to limit applications to a manageable number, and that means that, too often, we rely on indicators that are not actually indicators of what we care about," she says.

Although the University of Michigan is not particularly close to any minority-serving institutions, four campus departments have started master's programmes, based on the Fisk-Vanderbilt model, in ecology and environmental biology, molecular, cellular and developmental biology, applied mathematics and applied physics. In addition, the American Physical Society now funds similar bridge-to- $\mathrm{PhD}$ programmes at Ohio State University in Columbus and the University of South Florida in Tampa.

Edmund Bertschinger, institute community and equity officer at the Massachusetts Institute of Technology in Cambridge, which has its own physics bridge programme, says that the Fisk-Vanderbilt programme has amazingly dedicated faculty members and staff that watch out for and support one another. "They don't let students slip through the cracks."

Bertschinger and Stewart say that all graduate programmes could boost the pipeline persistence of alumni by taking a closer look at the 'grit factor' and other personality measurements when deciding which students to admit. After all, persistence in the face of adversity describes most successful academic science endeavours. For all types of STEM graduate students entering US PhD programmes, only 50-65\% (depending on ethnicity, gender and discipline) complete their doctorates - a miserably low return on investment for the time and money spent training students.

Participation in the bridge programme does not provide automatic admission to Vanderbilt — students must apply formally and meet all of the requirements. Isler decided to apply to other PhD programmes as well and was admitted to the astronomy programme at Yale University in New Haven, Connecticut. Stassun gently but firmly encouraged her to leave the bridge programme and follow her Ivy League dream. "That was the most generous thing anyone has ever done for me," she says.

On her first day at Yale, she felt out of place as the sole black woman, and also for her acute lack of pedigree. No one in her class knew what a historically black institution was, and no one had heard of Norfolk State or Fisk. "At a different time in my life, that would have crushed me," she says. But her time in the Fisk-Vanderbilt programme had given her the confidence to keep going. And her bridge family was never more than a phone call away.

In October, Isler defended her thesis work on blazars - hyperactive supermassive black holes that spew out accelerated particles. She became the first black woman to graduate from Yale with a PhD in astronomy and has already begun a Chancellor's Faculty Fellowship at Syracuse University in New York, a post that provides a transition to a tenuretrack faculty position. "You climb as high as you can," she says, "and then you guide the next person, who may go higher."

Kendall Powell is a science writer based in Lafayette, Colorado.

\section{EQUALITY}

\section{Lack of female leaders}

Women chair just $12 \%$ of all UK highereducation governing bodies and lead 17\% of UK institutions as vice-chancellors, says a study. Leaders in Higher Education 2013, released by the non-profit group WomenCount in Cardiff, says that the low numbers of women in leadership roles at institutions do not accurately reflect the proportion of female faculty members and students. Unconscious bias might be partly to blame for the numbers because people often appoint and promote others who are like themselves, the report suggests. Author Norma Jarboe, director of WomenCount, says that women must seek sponsors who will help them to get promotions, and pursue a position on the board of a company or charity. "Cross-sector knowledge and powerful contacts can be door openers," she says.

\section{RECESSION}

\section{Focus on outcomes}

The global recession has led governmentfunded academic science to focus increasingly on 'targeted outcomes' with a clear societal or economic impact, finds a report. The State of Higher Education 2013, released on 1 December by the Organisation for Economic Co-operation and Development in Paris, polled presidents and rectors at 34 highereducation institutions across 29 nations. Researchers are also spending a lot of time on public outreach, it finds. "If taxpayers understand the value of the research, they're more likely to agree to fund it," says report co-author Ellen Hazelkorn, vice-president of research and enterprise at the Dublin Institute of Technology. She suggests that early-career researchers polish their communication skills and focus on interdisciplinary work.

\section{COMMUNICATION}

\section{Internet freedom}

US faculty members are entitled to discuss issues relevant to the public on social media, argues a draft report. Academic Freedom and Electronic Communications, released on 3 December by the American Association of University Professors in Washington DC, notes that faculty members in some states have been suspended or dismissed for writing on Facebook or Twitter about controversial issues such as religion and gun control. Academics should be involved in creating social-media policies, the report says. 